above studies. The indications to start treatment were unclear, but included repeated seizures, especially occurring during waking hours. Relapses after AED withdrawal occurred in $14 \%$ of patients.

The functional organization of the interictal spike complex in benign rolandic epilepsy, also called BECT, was studied at the Universitatsklinik fur Neurologie, Donauspital; and Kinderklinik Glanzing, Vienna, Austria. (Baumgartner C, Graf M, Doppelbauer A, et al. Epilepsia Dec 1996;37:1164-1174). The interictal epileptiform spike complex is generated by multiple, simultaneously active neuronal populations within the central region.

\title{
ABSENCE EPILEPSY PSYCHOSOCIAL OUTCOME
}

The long-term psychosocial outcome in 56 patients aged 18 years or older with typical absence epilepsy and 61 controls with juvenile rheumatoid arthritis (JRA) was studied at the Royal University Hospital, Saskatoon, Saskatchewan, and the Izaak Walton Killam-Grace Health Center, and Dalhousie University Faculty of Medicine, Halifax, Nova Scotia, Canada. Structured interviews were conducted at a mean age of 23 years. More patients with absence epilepsy than with JRA had remission at follow-up (57\% vs $28 \%$ ). Patients with absence epilepsy had greater difficulties in school than those with JRA, and were less likely to graduate from high school. They also had a higher incidence of behavioral problems, a higher rate of unplanned pregnancy among women, they were more likely to drink alcohol to excess, have poor relationships with siblings, few friends, worked for fewer months in a year, more often in unskilled jobs, and more frequently dissatisfied with their employment. Patients with uncontrolled seizures had the poorest psychosocial outcome. (Wirrell EC, Camfield CS, Camfield PR et al. Long-term psychosocial outcome in typical absence epilepsy. Sometimes a wolf in sheeps' clothing. Arch Pediatr Adolesc Med Feb 1997;151:152-158). (Respond: Dr Carol S Camfield, Department of Pediatrics, Izaak Walton Killam-Grace Health Center, 5850 University Ave, Halifax, Nova Scotia, Canada B3J 3G9).

COMMENT. Chronic illness in childhood has an adverse effect on psychosocial behavior, absence epilepsy having a worse outcome than juvenile rheumatoid arthritis. Patients with uncontrolled seizures have the poorest prognosis, but factors related to treatment and control of seizures such as AED side-effects do not affect the outcome. Categories of adverse psychosocial outcome include academic-personal, behavioral, employmentfinancial, family relations, and social-personal relations. The journal editor, Catherine D DeAngelis comments:"Apparently much more than medications needs to be monitored and adjusted" in the management of children with absence epilepsy. In my practice, a factor which concerns adolescents with epilepsy above all others is the permit to drive an automobile. This question has far reaching psychosocial implications for young people and needs to be addressed fully with the patient and parents.

Juvenile diabetes is usually compared to absence epilepsy, when explaining the hardships of treatment and prognosis to a newly diagnosed young patient. I am wondering how these diseases would have contrasted in terms of psychosocial outcome, since both have no outward evidence of physical incapacity, unlike JRA, both require daily medication, and both are long-term chronic illnesses. 